\title{
VARIATIONS IN THE DUCT SYSTEM OF PANCREAS: A CADAVERIC STUDY
}

\author{
Narayanan Govindraj *1, Shabna.C 2 .
}

${ }^{1}$ Department of Anatomy, Government medical college Calicut, Kerala, India.

${ }^{* 2}$ Senior Resident, Department of Anatomy, Government medical college Calicut, Kerala, India.

\section{ABSTRACT}

Background: Recently there has been growing interest in the duct system of pancreas as concerns its relationship with various disease processes as well as newer investigatory and treatment modalities related to them.This study has been aimed at evaluating the anatomy of the pancreatic duct system, thus identifying the variants to improve our knowledge of it and make things easier. The pancreas is formed by the fusion of the ventral and dorsal anlage, and a wide spectrum of anomalies or anatomical variations may appear related to this complicated process of fusion: e.g., agenesis, aplasia of a pancreatic anlage, hypoplasia, annular pancreas, pancreas divisum or nonfusion of the ventral and dorsal duct system, pancreaticobiliary maljunction, etc. Every endoscopist who engages in pancreatography or related diagnostic and therapeutic procedures should always be aware of all sorts of anatomical variations he or she might encounter.

Materials and Methods: The pancreatic duct system of 50 adult human specimens were demonstrated by casting with acrylic resin using postmortem preparations

Results: The normal anatomic variants of the main pancreatic duct(duct of Wirsung) and accessory pancreatic duct(duct of Santorini) have been shown. In $52 \%$ of specimens, the major pancreatic duct followed the usual pattern and opened into the major duodenal papilla. Accessory pancreatic ducts were present in $48 \%$ of the cases. Variations in patterns of the main duct, collecting ducts, ductules have been noted. Patterns related to certain conditions of pancreas were noted. No herring bone pattern was observed. The pancreatic duct system was classified.

Conclusion: From the present study, it is concluded that knowledge of variation of pancreatic duct system can be used treatment of various diseases like pancreatitis pancreatic necrosis, or acute pancreatic fluid collections, chronic pancreatic fistulae and during procedures like ERCP, MRCP, EUS-guided pancreaticogastrostomy (EPG), transpapillary endoprostheses, Resective or decompressive pancreatic surgery etc.

KEY WORDS: Pancreatitis, Duct System, Duct Of Wirsung, Duct Of Santorini, Pancreas Divisum.

Address for Correspondence: Dr Shabna C, Senior Resident, Department of Anatomy, Government medical college Calicut, Kerala, India. Pin 673008 E-Mail: drshabnac@gmail.com

\begin{tabular}{|c|c|c|}
\hline \multicolumn{3}{|c|}{ Access this Article online } \\
\hline \multirow{2}{*}{$\begin{array}{l}\text { Quick Response code } \\
\text { Dol: } 10.16965 / \text { ijar.2017.269 }\end{array}$} & \multicolumn{2}{|c|}{$\begin{array}{l}\text { Web site: International Journal of Anatomy and Research } \\
\qquad \text { ISSN 2321-4287 } \\
\text { www.ijmhr.org/ijar.htm }\end{array}$} \\
\hline & $\begin{array}{l}\text { Received: } 26 \text { May } 2017 \\
\text { Peer Review: } 26 \text { May } 2017 \\
\text { Revised: None }\end{array}$ & $\begin{array}{l}\text { Accepted: } 10 \text { Jul } 2017 \\
\text { Published (O): } 31 \text { Jul } 2017 \\
\text { Published (P): } 31 \text { Jul } 2017\end{array}$ \\
\hline
\end{tabular}

\section{BACKGROUND}

In the event of increasing dependence on imaging investigations in todays clinical settings, it is crucial to be fluent in anatomical variations. The pancreas and its duct system is a frequently encountered matter in gastroenterology. The controversial association of pancreatitis and pancreas divisum was studied and concluded that pancreas divisum is but one variety of pancreatic anatomy [1]. Patients with acute relapsing pancreatitis were found to have drainage of the main pancreatic duct through the duct of 
Santorini and accessory papilla by endoscopic retrograde pancreatography. No other cause of pancreatitis was identified [2] Patency of the accessory pancreatic duct (APD) may depend on duct caliber, course, and terminal shape of the APD. A patent APD may prevent acute pancreatitis by reducing the pressure in the main pancreatic duct. Pancreas divisum is a common anatomical variation in which the ventral and dorsal pancreatic ducts do not unite during development. As the majority of exocrine flow is routed through the minor papilla in individuals with pancreas divisum, interrelationships between poor function of the minor papilla and increased flow of pancreatic juice caused by alcohol or diet may increase dorsal pancreatic duct pressure and lead to the development of pancreatitis. Wire-guided minor sphincterotomy, followed by dorsal duct stenting, is recommended for acute recurrent pancreatitis associated with pancreas divisum [3].

Although ductal disruptions are common in persistent, smoldering pancreatitis, pancreatic necrosis, or acute pancreatic fluid collections, chronic pancreatic fistulas have traditionally been defined as internal or external. Closure of these fistulas depends upon site and size of duct disruption, superinfection, downstream obstruction as a consequence of stricture or stone, or the presence of the "disconnected duct syndrome." Medical treatment is aimed at minimizing pancreatic secretion . Resective or decompressive pancreatic surgery requires preoperative ERCP to define the anatomy. More recently, transpapillary endoprostheses have been used in a patient subset and deserve additional consideration in patients who fail to respond to conservative measures[4].

Endoscopists are well advised to be familiar with the ontogenic variants in the pancreas and its duct system. Of particular importance is the anomaly of "pancreas divisum" that can be marked by isolated pancreatitis[5].

Magnetic resonance cholangiopancreatography (MRCP) is used for noninvasive work-up of patients with pancreaticobiliary disease. MRCP is comparable with invasive endoscopic retrograde cholangiopancreatography (ERCP) for diagnosis of extrahepatic bile duct abnormalities. In patients with biliary-enteric anastomoses, MRCP is also accurate in detection of pancreas divisum[6].

EUS-guided pancreaticogastrostomy (EPG) has been reported as an alternative to surgery in cases of pancreatic stricture where ERCP is unsuccessful. EUS-guided puncture and opacification of the pancreatic duct is performed, creating a transgastric fistula with placement of a guidewire into the main pancreatic duct and subsequent ductal decompression with a plastic endoprosthesis. The main outcome measurements used were Mean main pancreatic duct size, pain score, and weight before and after intervention [7].

Pancreatic ductal anatomy can predict the likely success of percutaneous drainage of pseudocysts of the pancreas [8].

\section{MATERIALS AND METHODS}

The material examined consisted of adult human pancreas and casts of pancreas. A total of 50 pancreas were studied by casts.

Casts were prepared from fifty pancreas. The cast material consisted of Acrylic repair material used in dentistry, available in two colors, pink and clear. This liquid prepared resin was immediately injected, since it begins to set in less than a minute or so.

The pancreas, along with a segment of duodenum including the first three parts and common bile duct, were removed and then washed with tap water thoroughly. The duodenum was cut open and cleaned. The major duodenal papilla was identified and cannulated with $18 \mathrm{G}$ infant feeding tube and the common bile duct was clamped. The cast material was prepared and then immediately injected into the canulated major duodenal pappilla, the end point being when the cast material exited via regurgitated through the injection site(around 7-10 ml). The major duodenal papilla was ligated and kept aside for the material to set, and the pancreas was placed in formalin for 24 hours for the cast to set properly. The next day the pancreas was placed in a glass jar containing concentrated hydrochloric acid. After a period of $24-48$ hours the pancreas was removed from the acid, washed under running tap water to remove acid and any tissue debris attaching itself to the cast. Once clean, the casts were air dried and the 
minute branches were trimmed to observe the patterns better. The branches and the branching pattern of the major pancreatic duct as well as that of minor pancreatic duct were studied.

Fig. 1: Commencement of main pancreatic duct.

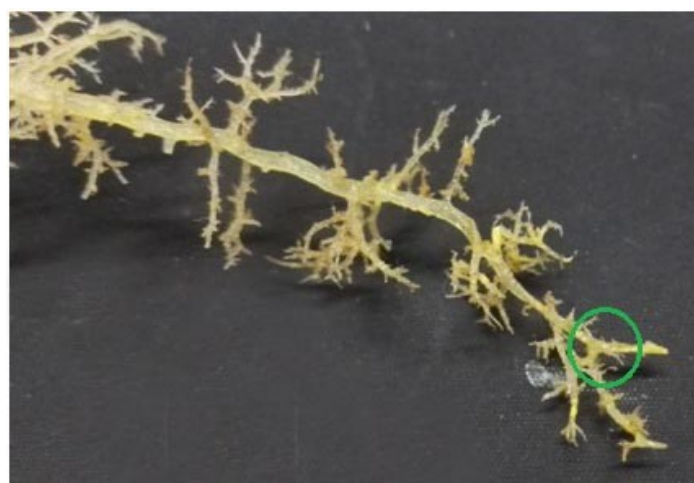

Fig. 2: Bare area between neck and body.

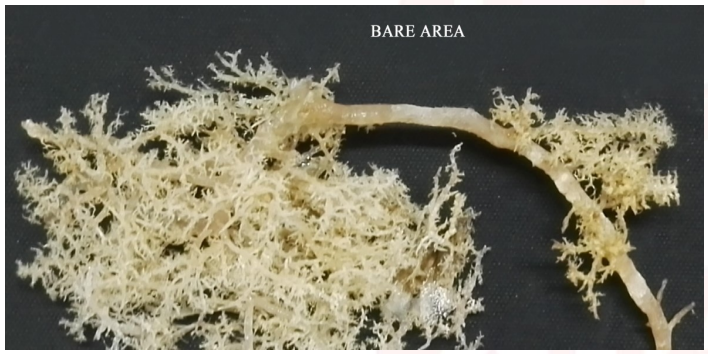

Fig. 3: Atretic accessory pancreatic duct.

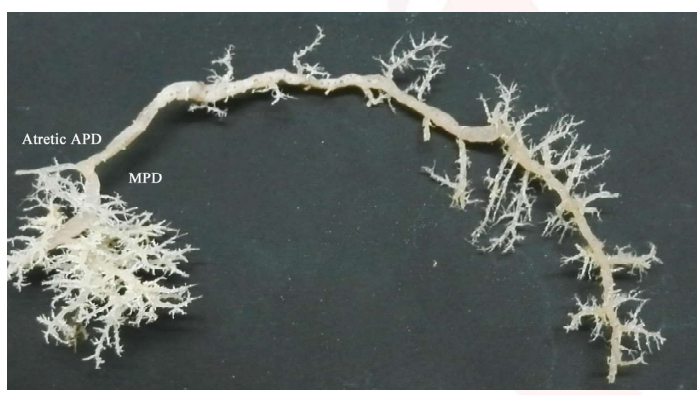

Fig. 4: The loop of ansa pancreatica.

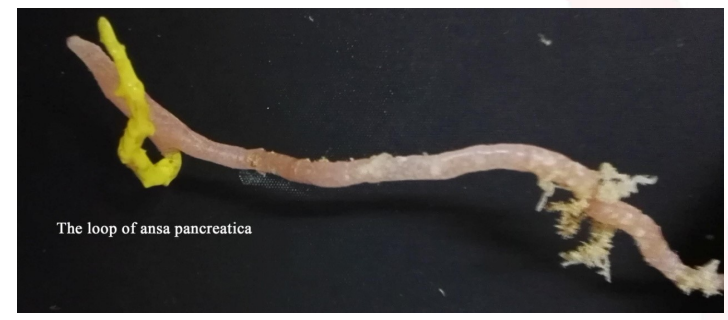

RESULTS

The formation of the major pancreatic duct(MPD) was by joining of two or more fine tributaries in the tail region. There was no specific pattern of commencement observed (fig 1). In some it began as bifid, some it was more than two ducts.

The course of the duct varied depending on the shape of the pancreas. The largest length noted was $15 \mathrm{~cm}$ and the smallest was $7 \mathrm{~cm}$, mean being $11.1 \mathrm{~cm}$.
Graph 1: frequency of lengths of MPD.

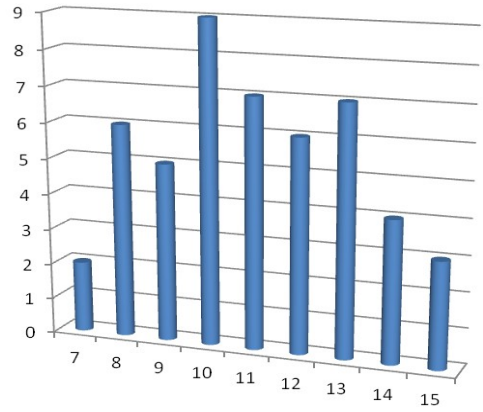

- NUMBER OF MPD STUDIED

From the neck of the pancreas, MPD turned caudally to the right towards the opening in the duodenum. It then took a horizontal course at around the level of major duodenal papilla; a few were slightly curved. This then passed towards the medial wall of second part of duodenum. When nearing the medial wall of the descending part of the duodenum, the major pancreatic duct and bile duct proceeded side by side and pierced the outer coat of the duodenal wall, both had an oblique course and joined together to form a common channel which opened at the summit of the major duodenal papilla.

The diameter of the major pancreatic duct was measured separately in head, body and tail. The average diameters of the major pancreatic duct was $2.9 \mathrm{~mm}$ in the head, $2.33 \mathrm{~mm}$ in the body, and $1.49 \mathrm{~mm}$ in the tail portion.

Table 1: Dimensions of the major pancreatic duct.

\begin{tabular}{|c|c|c|c|c|c|}
\hline \multicolumn{5}{|c|}{ Width of the major pancreatic duct at various sites } \\
\hline \multicolumn{2}{|c|}{ head } & \multicolumn{2}{c|}{ body } & \multicolumn{2}{c|}{ tail } \\
\hline range $(\mathrm{cm})$ & $\%(\mathrm{n}=50)$ & range $(\mathrm{cm})$ & $\%(\mathrm{n}=50)$ & range $(\mathrm{cm})$ & $\%(\mathrm{n}=50)$ \\
\hline$<2$ & 3 & $<2$ & 7 & $<1$ & 1 \\
\hline $2-3.5$ & 43 & $2-2.5$ & 26 & $1-1.5$ & 28 \\
\hline$>3.5$ & 4 & $>2.5$ & 17 & $>1.5$ & 21 \\
\hline
\end{tabular}

The diameter of the duct increased from tail to head of the pancreas as it receives further lobular ducts, that join it almost all kinds of angles. The lobular ductules varying in number from 20 to 62 mostly opened along the superior and inferior aspects of the major pancreatic duct. A few opened along the anterior and posterior aspects of the major pancreatic duct. The angles of joining of these ductules to the major pancreatic duct were variable and did not adhere to any specific pattern. No herringbone pattern was observed. The distance between two adjacent ductules at their openings varied from .5 to $10 \mathrm{~mm}$. 
Bare areas are places showing no lobular ducts in the MPD. Two of the specimens showed bare areas in the region between neck and body in spite of evidence of terminal filling. In one of the specimens, the MPD had fewer lobular ducts joining it after the bare area, ie, in the body and tail region of MPD, comparing with others.

Accessory pancreatic duct: An accessory pancreatic duct also called the Duct of Santorini usually drains into to the duodenum via the minor duodenal papilla. An accessory pancreatic duct was present in almost half of the study group. It was considered to be absent or as case of pancreas divisum when it could not be injected through major duodenal papilla. Depending on the APD, pancreatic duct system as found in the adult specimens, was classified in 3 groups as done by Bermann et al [17].

\section{Group A :without Santorini \\ Group B: with Santorini \\ Group C: blind Santorini}

Around half of the specimens had an accessory duct. Type A was seen in 52 \%.Type B in $40 \%$ and Type $C$ in $8 \%$.

Atretic ducts: Though many specimens had an accessory pancreatic duct, not all were open into the duodenum. There was atretic accessory pancreatic duct (fig 3 ) in two specimens, ie, they have connection with MPD, but do not open in the minor duodenal papilla. Only the MPD opens into the duodenum.

Ansa pancreatica: One specimen in the study showed ansa pancreatica (fig 4) pattern. The main characteristic of this particular group is obliteration of the accessory pancreatic duct at the place of connection with Wirsung's duct and replacement of it by an additional communication between the dorsal and ventral duct system.

\section{DISCUSSION}

The formation of the major pancreatic duct was by joining of two or more fine tributaries in the tail region. There was no specific pattern of commencement observed in the present study like single, bifid etc. The same was reported by Sahni Det al [9].

From the neck of the pancreas, it turned caudally to the right towards the opening in the duodenum. It then took a horizontal course at around the level of major duodenal papilla; a few were slightly curved. This then passed towards the medial wall of second part of duodenum. When nearing the medial wall of the descending part of the duodenum, the major pancreatic duct and bile duct proceeded side by side and pierced the outer coat of the duodenal wall, both had an oblique course and joined together to form a common channel which opened at the summit of the major duodenal papilla .This is highly in accordance with the study conducted by Sahni D et al [9].

In the present study, the length of the major pancreatic duct ranged from $7 \mathrm{~cm}$ to $15 \mathrm{~cm}$. In the study by Kang JK [10], the length of the pancreatic duct was $17.5 \pm 2.8 \mathrm{~cm}$. A study on normal pancreatic morphology done by Kochhar et al [11], the mean length of PD was $18.2 \pm 3.0$ $\mathrm{cm}$, being longer in males but not varying with age. Sahni $D$ et al [9] got a mean curvilinear distance of the duct $17.1 \pm 1.59 \mathrm{~cm}$ in the male and $15.1 \pm 1.38 \mathrm{~cm}$ in the female. In a descriptive cross sectional study by Ara et al [11] the main pancreatic duct length measurements gave a mean $\pm S D$ as $16.13 \pm 3.26 \mathrm{~cm}$. In the present study, the mean length of main pancreatic duct is 11.1 , which does not corresponding to any of the above studies.

Table 2: Comparing the mean length in $\mathrm{cm}$ for various studies

\begin{tabular}{|c|c|}
\hline Name of study & Mean length in cm \\
\hline Kang jk [10] & $17.5 \pm 2.8$ \\
\hline Kochhar[11] & $18.2 \pm 3$ \\
\hline Sahni d[9] & $\begin{array}{c}17.1 \pm 1.59(\mathrm{M}) \\
15.1 \pm 1.38(\mathrm{~F})\end{array}$ \\
\hline Ara[12] & $16.13 \pm 3.26$ \\
\hline Present study & 11.1 \\
\hline
\end{tabular}

The diameters of the main pancreatic duct was measured in the head, body and tail and mean ductal diameters were reported by Varley et al [13] as 3.1,2.0 and $0.9 \mathrm{~mm}$ in the head, body and tail of the pancreas respectively. Hadid A [14] got the same as $3 \mathrm{~mm}$ in the head, 2.1 and $1.6 \mathrm{~mm}$ in the body proximal to and distal to the neck respectively. Kang et al [10] analyzed pancreatograms and got the diameter of the pancreatic duct as $3.30 .8 \mathrm{~mm}$ in the head, 2.4 $\pm 0.5 \mathrm{~mm}$ in the body and $1.5 \pm 0.5 \mathrm{~mm}$ in the tail portion. Mean ductal diameters in the head, body and tail of the pancreas were $2.63,1.95$, $0.99 \mathrm{~mm}$ in individuals aged less than or equal 
to $40 \mathrm{yr}$ and $3.31,2.34,1.23 \mathrm{~mm}$ in those greater than $40 \mathrm{yr}$, respectively according to a study by Karak et al. [15]. The upper range of normal pancreatic duct width was $8.0 \mathrm{~mm}, 4.0 \mathrm{~mm}$ and 2.4 $\mathrm{mm}$ in the head, body and tail, respectively in a study done by Ladas et al. [16] According to Kochhar et al [11] the mean of the maximum diameters of PD in head, body and tail were 3.7 (0.8), $2.7(0.6)$ and $1.7(0.4) \mathrm{mm}$ respectively. In the present study, the mean diameters of head, body and tail were 2.9,2.3,1.5 respectively.

Graph 2: Mean Diameter of Head.

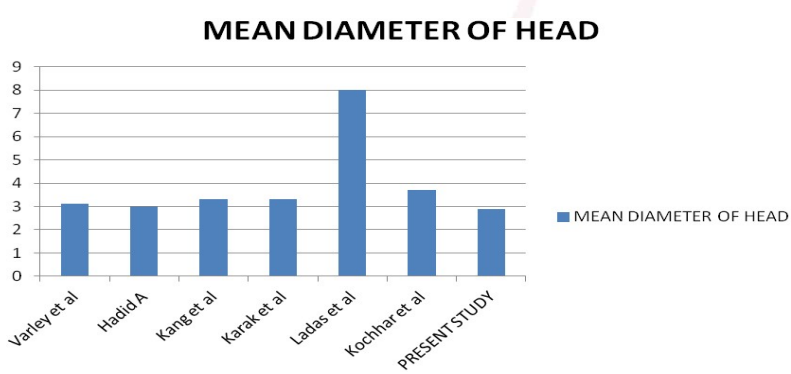

The mean diameter of head in the present study was $2.9 \mathrm{~mm}$ which is in accordance with the above studies except that of Ladas $^{[16]}$ et al. The relative decrease in diameter of head in the present study could be accounted by the shrinkage of the resin after setting.

Graph 3: Mean Diameter of body. mean diameters of body

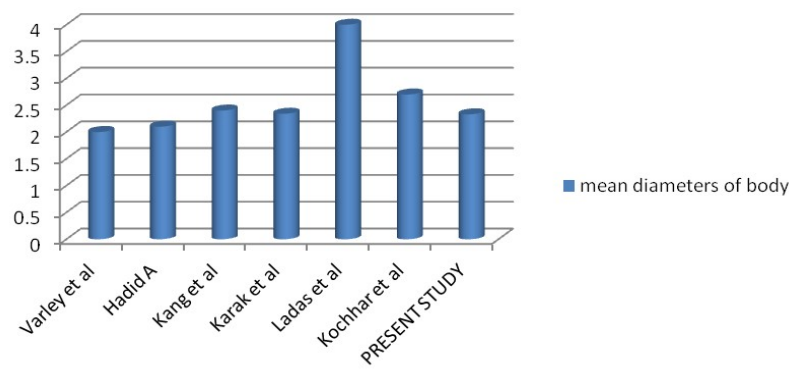

The average diameter of the body in the present study was $2.33 \mathrm{~mm}$ which is in closely resembling the referred studies except that by Ladas ${ }^{[16]}$ et al. This significant difference may be due to the fact that they studied upper ranges of normal pancreatic ducts in people with a diagnosis of pancreatic disease. This difference concludes that establishing normal ranges of the pancreatic duct width may help in the diagnosis of pancreatic disease.

Hadid A [14] had not reported diameter of the tail of MPD as the study was ultra sound based. The tail of the pancreas is very difficult to be identified on ultrasound.
Branching pattern of the major pancreatic duct: In the present study, the lobular ductules varying in number from 20 to 62 mostly opened along the superior and inferior aspects of the major pancreatic duct. A few opened along the anterior and posterior aspects of the major pancreatic duct. The angles of joining of these ductules to the major pancreatic duct were variable and did not adhere to any specific pattern. No herringbone pattern was observed. The distance between two adjacent ductules at their openings varied from .5 to $10 \mathrm{~mm}$. According to Sahni $D^{[9]}$, Twenty to thirty five lobular ducts opened on either side of the MPD while a few opened on the anterior or posterior walls. There was no 'herringbone' arrangement. The distance between the two ductules varied from 1 to 10 $\mathrm{mm}$. Thus the present study closely resembled that of Sahni D [9], but is in variance with a few literatures.

Graph 4: Mean Diameter of tail of MPD.

mean diameters of tail of MPD

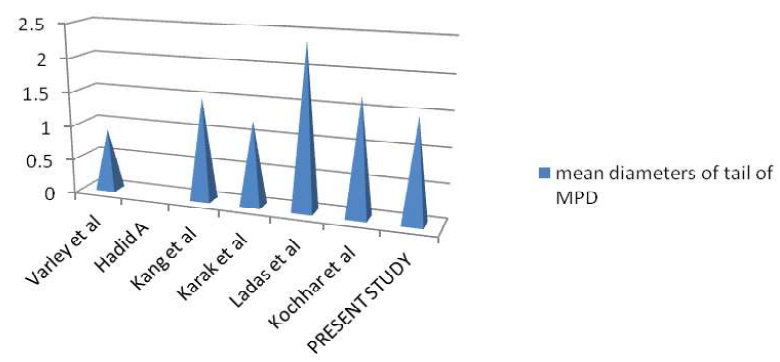

Bare areas: Two of the specimens showed bare areas in the region between neck and body in spite of evidence of terminal filling. Instances of similar cases were reported by Bermann ${ }^{[17]}$ et al associated with Laennecs cirrhosis and history of alcoholism. Since the present study did not take into account the alcoholic status of the subjects, this could not be correlated.

Accessory pancreatic duct: The accessory pancreatic duct,also known as duct of Santorini, was found in about half of the specimens.(48\%). This coincides with studies done by Toda et al [18] and Dawson and Langman [19]. Mc carthy et al [20] has reported only $21 \%$ accessory ducts in his study population. Karak et al [15], studied normal endoscopic pancreatograms and the duct of Santorini was visualised in 6.6 per cent subjects. Toda et al [18] demonstrated pancreatic ducts with MR cholangiography and visualization of accessory pancreatic duct was $42 \%$. 
Wilasrusmee et al [21] through dissection studies , traced accessory ducts to the duodenal wall in $57.2 \%$ cases. Sahni $D$ et al [9] through cast studies could visualize accessory ducts in $94.4 \%$ of males and $85.7 \%$ females. Patent accessory ducts were traced by Dawson and Langman [19] in $40 \%$ of his study group. Bermann et al [17] found $33 \%$ patent accessory ducts in his cast studies.

Table 3: Comparing the $\%$ Presence of APD with various studies.

\begin{tabular}{|c|c|}
\hline Name of study & $\begin{array}{c}\text { \% presence of } \\
\text { APD }\end{array}$ \\
\hline McCarthy et al[20] & 21 \\
\hline Karak et al[15] & 6.6 \\
\hline Toda et al[18] & 42 \\
\hline Wilasrusmee et al[21] & 57.2 \\
\hline Sahni D et al[9] & $94.4,85.7$ \\
\hline Dawson and Langman[19] & 40 \\
\hline Bermann et al[17] & 33 \\
\hline PRESENT STUDY & 48 \\
\hline
\end{tabular}

Classification of pancreatic duct system: According to the accessory pancreatic duct, as found in the adult specimens, was classified in 3 groups as done by Bermann et al.[17]

Group A :without Santorini

Group B: with Santorini

Group C: blind Santorini

Around half of the specimens had an accessory duct. Type A was seen in $52 \%$.Type B in $40 \%$ and Type $C$ in $8 \%$.

Dawson and Langman [19] classified pancreatic duct system in to the following 4 groups:

Group 1: embryonic type- the two duct systems failed to fuse

Group 2: patent accessory duct-dorsal and ventral ducts have fused and two openings in the duodenal walls.

Group 3: accessory duct replaced by ansa pancreatica

Group 4: accessory duct partly or completely obliterated.

An obliterated accessory duct was seen in cases. Dawson and Langman[19] observed this in $35 \%$ of their specimens. One case of ansa pancreatica was identified in the present study. Sahni D[9] classified pancreatic ducts based on the accessory pancreatic duct. The following patterns of accessory pancreatic ducts were identified:

Type 1: when APD commenced from the main pancreatic duct in the neck of the pancreas and extended to the right to open at the minor duodenal papilla. This type was further subdivided into two subtypes $A$ and $B$.

$A$ : when it received tributaries from the upper part of the head

B: when it also received tributaries from the lower part of the head

Type 2: when APD started from the lower part of the head and ascending anterior to the MPD, it opened at the minor duodenal papilla. This type could be of two types-A and B.

$A$ :at the crossing of the APD and MPD, there was a communication between the two ducts.

B:there was no communication between the two ducts.

Type 3: Embryonic type. MPD opened at the minor duodenal papilla.APD opened at the major duodenal papilla with CBD. No connection between the two (pancreas divisum). This condition is also known as isolated ventral pancreas.

Pancreas divisum: In the present study, when both ducts could not be cast through the major duodenal papilla, and the other had to be cast separately through the minor duodenal papilla, it was considered as a case of pancreas divisum.

Ansa pancreatica: One specimen in the study showed ansa pancreatica pattern. Wirsung's duct and replacement of it by an additional communication between the dorsal and ventral duct system. During the course of embryological development, the accessory pancreatic duct or the duct of Santorini undergoes a variable degree of atrophy at its duodenal end. This variable degree of obliteration results in varying patency rates of the accessory duct where it enters the minor papilla, and also a variable course and shape of the accessory pancreatic duct. Ansa pancreatica is a type of ductal anatomy which was named by Dawson and Langman[19] and is characterized by obliteration of the accessory pancreatic duct at its junction with the ventral pancreatic duct, and replacement of this duct by an additional arched communication between the dorsal and ventral duct systems. This arched duct is formed by the combination of the proximal duct of the dorsal 
pancreatic bud, the inferior branch of the duct of the dorsal pancreatic bud and the inferior branch of the duct of the ventral pancreatic bud. Thus, in the ansa pancreatica type of ductal variation, the accessory pancreatic duct arises from the main pancreatic duct and loops, running an arched course into the caudal portion of the pancreas, turning anterior to the main duct to terminate in or around the minor papilla. Dawson and Langman [19] observed 21 cases of ansa pancreatica in their study. Though it seemed to replace the direct communication between combined pancreatic duct and the duodenum, its entrance into the duodenum was not always patent. When eosin was injected into the tail end of the duct, it appeared at the minor papilla in 7 of the 21 cases. In the remaining cases, the minor papilla was clearly visible, but the entrance of the duct was obliterated.

In the present study, the ansa pancreatica was patent into the minor duodenal papilla.

\section{CONCLUSION}

The pancreatic duct system of 50 adult specimens were demonstrated by casting with acrylic resin using postmortem preparations. The normal anatomic variants of the ducts of Wirsung and Santorini have been shown. In $52 \%$ of specimens, the major pancreatic duct followed the usual pattern and opened into the major duodenal papilla. Accessory pancreatic ducts were present in $48 \%$ of the cases.Variations in patterns of the main duct, collecting ducts, ductules have been noted. Patterns related to certain conditions of pancreas were noted. No herring bone pattern was observed. The pancreatic duct system was classified.

\section{Conflicts of Interests: None}

\section{REFERENCES}

[1]. Warshaw AL, Simeone JF, Schapiro RH, FlavinWarshaw B. Evaluation and treatment of the dominant dorsal duct syndrome (pancreas divisum redefined). Am J Surg. 1990 Jan;159(1):59-64; discussion 64-6

[2]. Heiss FW, Shea JA.Association of pancreatitis and variant ductal anatomy: dominant drainage of the duct of Santorini. Am J Gastroenterol. 1978 Aug;70(2):158-62.

[3]. Kamisawa T. Clinical significance of the minor duodenal papilla and accessory pancreatic duct. J Gastroenterol. 2004 Jul;39(7):605.
[4]. Kozarek RAEndoscopic therapy of complete and partial pancreatic duct disruptions. Gastrointest Endosc Clin N Am. 1998 Jan;8(1):39-53

[5]. W. Rösch,H. Koch, MD, O. Schaffner, MD,L. Demling, $M D$. The clinical significance of the pancreas divisum. GIE, May 1976Volume 22, Issue 4, Pages 206-207

[6]. Ahmet Mesrur Halefoglu. Magnetic resonance cholangiopancreatography: A useful tool in the evaluation of pancreatic and biliary disorders; World J Gastroenterol. 2007 May 14; 13(18): 25292534.

[7]. Kahaleh M, Hernandez AJ, Tokar J, Adams RB, Shami VM, Yeaton P EUS-guided pancreaticogastrostomy: analysis of its efficacy to drain inaccessible pancreatic ducts.Gastrointest Endosc. 2007 Feb;65(2):224-30. Epub 2006 Dec 4.

[8]. Nealon WH, Walser E. Main pancreatic ductal anatomy can direct choice of modality for treating pancreatic pseudocysts (surgery versus percutaneous drainage). Ann Surg. 2002 Jun;235(6):751-8

[9]. Sahni D, Jit I, Harjeet. Gross anatomy of the pancreatic ducts in north Indians. Trop Gastroenterol. 2001 Oct-Dec;22 (4):197-201

[10]. Kang JK, Chung JB, Moon YM, Choi HJ .The normal endoscopic pancreatogram in Koreans. . Korean J Intern Med. 1989 Jan;4(1):74-9

[11]. Kochhar R, Goenka MK, Nagi B, Aggarwal R, Singh K.Normal pancreatic duct morphology in a north Indian population. Trop Gastroenterol. 1996 OctDec;17(4):223-5.

[12]. Ara S, Shahriah S, Begum S. The length of main pancreatic duct in Bangladeshi cadaver at different age groups. Mymensingh Med J. 2011 Apr;20(2):298302.

[13]. Varley PF, Rohrmann CA Jr, Silvis SE, Vennes JA .The normal endoscopic pancreatogram. Radiology. 1976 Feb;118(2):295-300

[14]. Hadidi A.Pancreatic duct diameter: sonographic measurement in normal subjects. J Clin Ultrasound. 1983 Jan;11(1):17-22.

[15]. Karak PK, Vashisht S, Tandon RK, Berry MNormal endoscopic pancreatogram in an Indian referral hospital. Indian J Med Res. 1991 Dec;94:426-9

[16].Ladas SD, Tassios PS, Giorgiotis K, Rokkas $\mathrm{T}$, Theodosiou P, Raptis SA Pancreatic duct width: its significance as a diagnostic criterion for pancreatic disease. Hepatogastroenterology. 1993 Feb;40(1):52-5.

[17]. Berman G.L.,Prior.T , Abramow. M, Ziegler .D, .A study of thee pancreatic duct system in man by the use of vinyl acetate casts of postmortem preparations. Surgery, Gynaecology, and Obstetrics, 110,391-403

[18].MacCarthy L.R.,Stephens H.D., Brown.L.A., Carlson.C.H. Retrograde pancreatography in autopsy specimens. Am J Roentgenol Radium Ther Nucl Med. 1975 Feb;123(2):359-66.

[19]. Wilasrusmee C, Pongchairerks P. Pancreaticobiliary ductal anatomy in Thai people. J Hepatobiliary Pancreat Surg. 1999;6(1):79-85. 
[20]. Dawson W, Langman J An anatomical-radiological study on the pancreatic duct pattern in man. Anat Rec. 1961 Jan;139:59-68.
[21]. Toda J, Ueno E, Takada Y, Okawa T. Demonstration of normal bile duct and pancreatic duct with MR cholangiopancreatography. Nihon Rinsho. 1998 Nov;56(11):2830-5.

How to cite this article:

Narayanan Govindraj, Shabna. C. VARIATIONS IN THE DUCT SYSTEM OF PANCREAS: A CADAVERIC STUDY. Int J Anat Res 2017;5(3.1):4136-4143. DOI: 10.16965/ijar.2017.269 